\title{
ESTUDO COMPARATIVO ENTRE MEIOS DE CAPTAÇÃO DE VAPORES DE MERCÚRIO PARA AVALIAÇÃO DO RISCO DE INTOXICAÇÃO PROFISSIONAL
}

Colacioppo, S. Estudo comparativo entre meios de captaçāo de vapores de mercúrio para avaliação do risco de intoxicação profissional. Rev. Saúde públ., S. Paulo, 11:389-94, 1977.

RESUMO: Estudo comparativo entre os meios de captação de vapores de mercúrio mais viáveis: absorção em permanganato de potássio em meio ácido, absorção em solução de iodo e iodeto, adsorção em carvão ativo e adorção em hopcalita. E descrito um processo de produção de atmosfera padrão de vapores de mercúrio para testar os diferentes meios, e o que maior acuidade e precisão apresentou foi o que utiliza absorşão em permanganato em meio ácido.

UnITERmos: Mercúrio, toxicologia. Medicina do trabalho. Saúde ocupacional.

\section{I N T R O D U G $\cong$}

O mercúrio em sua forma metálica e líquida encontra grande número de aplicações industriais, porém, os vapores que dele emanam originam risco de intoxicação profissional. De acordo com o que se verifica em estudos a respeito da avaliação do efeito sobre o organismo humano, como o realizado pelo U. S. Department of Health, Education and Welfare ${ }^{15}$ (1973), existe ainda grande dificuldade de estabelecer um paralelo perfeito entre os achados laboratoriais de análises de material biológico e sinais ou sintomas da intoxicação por mercúrio. Por outro lado, as medidas preventivas de ordem de higiene do trabalho não eliminam totalmente o risco de intoxicação, turnando necessária uma avaliação ambiental dos vapores de mercúrio, que servirá para correlacionar o quadro clinico do tra- balhador com a concentração a que possivelmente esteve exposto, ou ainda, para avaliar a eficiência das medidas de controle introduzidas.

Porém, para a realização de tal tarefa, o higienista industrial depara-se com o problema de qual meio de captação deverá utilizar, uma vez que a literatura especializada indica vários deles, não fazendo ainda referência à eficiência de captação ${ }^{1,}{ }^{4}, 5$, ${ }^{6}, \quad 7{ }^{11},{ }^{12}, 13$.

\section{MATERIAL E METODOS}

2.1. Produção de uma atmosfera de concentração conhecida de vapores de mercúrio

A fim de se realizar um estudo comparativo entre processos de captação de vapo-

\footnotetext{
* Do Departamento de Saúde Ambiental da Faculdade de Saúde Pública da USP - AD. Dr. Arnaldo, 715 - São Paulo, SP - Brasil.
} 
COLACIOPPO, S. Estudo comparativo entre meios de captação de vapores de mercúrio para avaliação do risco de intoxicação profissional. Rev. Saúde públ., S. Paulo, 11:389-94. 197.

res de mercúcio, há necessidade de se estabelecer uma atmosfera padrão onde se conheça exatanente o teor de mercúri, presente. É então proposto un equipa- mento, descrito a seguir, con a finalidade de produzir uma atmospera padrão que poderá ser amostrada por vários processos. (Figura).

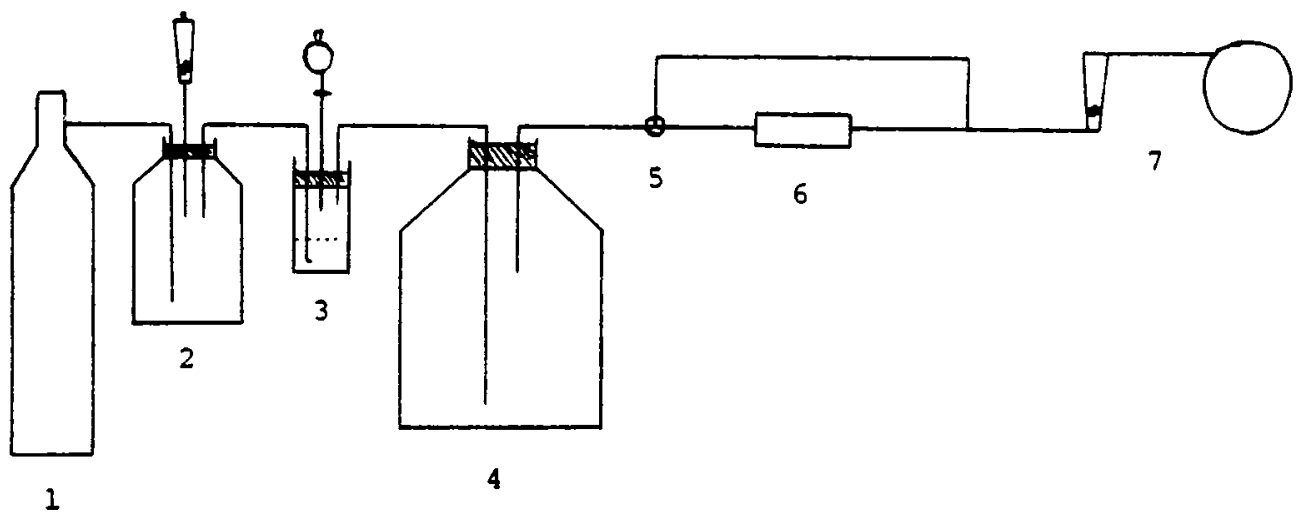

Utiliza-se nitrogênio ou ar comprimiclu, em cilindros a fim de se evitar possiveis contaminações provenientes do laboratório.

$O$ ar é levado a um frasco onde se mantém a uma pressão ligeiramente superior à do meio ambiente, de onde é aspirado, passando por um gerador de vapor de mercúrio; o gerador consta de um frasco borbulhador contendo $75 \mathrm{ml}$ de unia solução padrão de mercúrio à qual é adicionada, em momento oportuno, uma alicota de $5 \mathrm{ml}$ de cloreto estanoso. Essa adição provoca uma redução do mercúrio em solução para mercútio metálico, que, por borbulhamento, origina uma corrente de vapor de mercúrio que é aspirada para um frasco de $20 \mathrm{I}$ com a finalidade de diluir os vapores, evitandose, assim, picos de concentração que poderiam não ser eficientemente coletados.

A seguir acrescenta-se o elemento de captação, tendo, contudo, um desvio que proporciona uma aspiração direta pela bomba, facilitando, assim, a operação de calibração da vazão, sendo fechado o desvio simultaneamente ao inicio do borbulhamento no gerador e à adição de cloreto estanoso.

Desta maneira, fazendo-se passar un volume total de atmosfera de duas a três rezes o volume do frasco diluidor, teremos passado pelo elemento de captação praticamente todo o mercúrio existente na sulução padrão inicial, calculando-se, então. com facilidade, a concentração de vapor de mercúrio que foi produzida.

\subsection{Captaçio de Vapores de Mercurio}

Utilizando o equipamento descrito acima para a produção de vapores de mercúrio, foram realizadas várias captações, utilizando os seguintes meios de captação:

- pernianganato de potássio en meio ácido

- solução de iôdo

- hopcalita

- carvão ativo.

Estes meios de captação foram seleciunados pur serem os que apresentam maior aplicabilidade prática.

As técnicas empregadas foran as seguintes:

Para a captação com permanganato de potássio foram utilizados dois borbulhadores em série, de vidro pyrex e dispersor 
COLACIOPPO, S. Estudo comparativo entre meios de captação de vapores de mercúrio para avaliação do risco de intoxicação profissional. Rev. Saúde públ., S. Paulo, 11:389-94, 1977.

de vidro sinterizado, con capacidade de 30 ml, contendo cada um $5 \mathrm{ml}$ de solução de permanganato de potássio $0,5 \mathrm{~N}$ e $5 \mathrm{ml}$ de ácido sulfúrico $2,0 \mathrm{~N}$. A vazão foi ajustada para 2 litros por minuto. Após a captação, unna alicota propriada da solução do borbulhador, é transferida para um balão de $200 \mathrm{ml}$, com adaptação para o mesmu tipo de borbulhador utilizado na captaçāo, e feita uma diluição para $100 \mathrm{ml}$. A este balão são adicionados $5 \mathrm{ml}$ de solução de cloridrato de hidroxilamina a $1,5 \%$ para reduzir o excesso de permanganato, e a seguir, com o borbulhador já conectado au espectrofutômetro, adicionam-se $5 \mathrm{ml}$ de solução de cloreto estanoso a $25 \% \mathrm{em}$ ácido cloridrico a $50 \%$ e faz-se a leitura $1 \%$.

A captação com solução de iôdo obedeceu basicamente au mesmo esquema utilizandu-se no borbulhador $10 \mathrm{ml}$ de uma solução de iôdo a $0,25 \%$ e jodeto de potássio a $3 \%$ segundo Jacobs. *

A captação com hopcalita foi realizada segundo a técnica descrita por Rathje ${ }^{1}$ utilizando-se hopcalita fornecida pela Mine Safety Applyancies Co. Foram preenchidas duas secções de tubos de vidro, de diâmetro interno de cerca de $2 \mathrm{~mm}$, com aproximadamente $0,5 \mathrm{~g}$ de hopcalita en cada secção, separadas por um tufo de lã de vidro, e estas analisadas separadamente. A eluição foi feita em ácido nítrico a $50 \%$ em quatro porções de $10 \mathrm{ml}$, diluindo-se a seguir em balão volumétrico a $100 \mathrm{ml}$. Desta solução uma alicota é transferida para un balão de $200 \mathrm{ml}$ provido de borbuthador e conectado ao analisador de mercúrio; adicionam-se $5 \mathrm{ml}$ de solução de cloreto estanoso a $25 \%$ em ácido cloridrico a $50 \%$ e faz-se a leitura.

A captação com carvão ativo foi realizada por processo semelhante ao descrito acima, utilizando-se, porém, carvão ativo de 20/40 malhas e impregnação de iôdo a $5 \%$, conforme Mantell 8 , utilizando-se uma eluição com ácido nítrico a $10 \%$.

\subsection{Análise do Material Captado}

As análises de mercurio foram efetuadas com equipamento Perkin-Elmer/Coleman, modelo MAS-50 - Mercury Analyser System, que utiliza basicamente o processo de absorção atômica sem chama, descrito por Hatch e Ott ${ }^{3}$.

Para cálculo das concentrações de vapores de mercúrio na atmosfera criada no laboratório, foram levadas em conta as diluiçues feitas durante o processo de captação e análise, a quantidade de soluçẫo padtão adicionada no gerador de vapor e o volume de atmosfera captado.

Foi utilizada solução Tritisol Merck solução padrão de mercúrio para espectrofotometria, tanto para calibração do instrumento como para produção de vapores.

$$
\text { 3. R E S L L T A D O S }
$$

Utilizando $2,6+\mu g$ de mercúrio no gerador e passando-se 20 litrus de atmosfera a uma vazão de 2 litros por minuto, obteve-se uma concentração de $132 \mu \mathrm{g}$ de vapores de mercúrio por metro cúbico. Foram realizadas avaliaçóes segundo os quatro processos descritos no item 2 e encontrados os valores constantes da Tabela.

\section{D I S C U S S $\mathbb{A} O$}

Considerando os resultados obtidos, verifica-se que o equipamento proposto para a produção de vapores de mercúrio funciona satisfatoriamente, uma vez que a média das avaliaçōes utilizando permanganato de potássio atingiu uma eficiência de $97,7 \%$ em relação ao padrão adicionado.

Outros processos de produção de uma atmosfera padrăo poderiam e foram considerados. Inicialmente poderiamos elaborar uma câmara de vários metros cúbicos, na qual se faz evaporar uma quantidade conhecida de mercúrio metálico, conforme descreve Mays e col. ${ }^{9}$ 
COLACIOPPO, S. Estudo comparativo entre meios de captação de vapores de mercúrio parn avaliação do risco de intoxicação profissional. Rev. Saúde públ., S. Paulo, 11:389-94, 1977.

T A B E L A

\begin{tabular}{|c|c|c|c|c|c|}
\hline \multirow[b]{2}{*}{$\begin{array}{l}\text { Ne da } \\
\text { amostra }\end{array}$} & \multirow[b]{2}{*}{$\begin{array}{l}\text { Volume } \\
\text { captado } \\
\text { (litros) }\end{array}$} & \multicolumn{4}{|c|}{ Processo de captação utilizado } \\
\hline & & $\begin{array}{c}\text { Permanganato } \\
\text { de potássio } \\
\mu \mathrm{g} / \mathrm{m3}\end{array}$ & $\begin{array}{l}\text { Iôdo } \\
\text { iodeto } \\
\mu \mathrm{g} / \mathrm{m} 3\end{array}$ & $\begin{array}{c}\text { Hopcalita } \\
\mu \mathrm{g} / \mathrm{m}:\end{array}$ & $\begin{array}{l}\text { Carvão } \\
\text { ativo } \\
\mu \mathrm{g} / \mathrm{n} \text { : }\end{array}$ \\
\hline 01 & 20 & 131,0 & 25,0 & 96,0 & 16.5 \\
\hline 02 & 20 & 127,5 & 12,5 & 116,5 & 10,0 \\
\hline 03 & 20 & 126,5 & 18,0 & 105,0 & 8,5 \\
\hline 04 & 20 & 138,0 & 18,0 & 126,5 & 0,5 \\
\hline 05 & 20 & 131,0 & 18,0 & 87,5 & 0.5 \\
\hline 06 & 20 & 140,0 & 12,5 & 93,5 & 9.5 \\
\hline 07 & 20 & 130,0 & 12,5 & 86,5 & 9,0 \\
\hline 08 & 20 & 136,5 & 8,5 & 94,0 & 12,5 \\
\hline 09 & 20 & 132,5 & 13,0 & 89,5 & 10,0 \\
\hline 10 & 20 & 122,5 & 16,5 & 89,0 & 8.0 \\
\hline 11 & 20 & 126,0 & 38,0 & 91,0 & 15.0 \\
\hline 12 & 20 & 125,0 & 25,0 & 113,5 & 10.5 \\
\hline 13 & 20 & 120,0 & 85.0 & 107,0 & 12.11 \\
\hline 14 & 20 & 137,5 & 22,0 & 90,0 & 90 \\
\hline 15 & 20 & 139,5 & 30,0 & 123,0 & 115 \\
\hline 16 & 20 & 120,5 & 40,0 & 90,5 & 10,0 \\
\hline 17 & 20 & 120,0 & 39,5 & 94,5 & 8,5 \\
\hline 18 & 20 & 122,5 & 29,0 & 96,0 & 10.5 \\
\hline 19 & 20 & 125,0 & 25.0 & 89,0 & 11.0 \\
\hline 20 & 20 & 128,0 & 28,5 & 86,5 & 7.5 \\
\hline \multicolumn{2}{|l|}{ Média } & 129,00 & 21,85 & 98,25 & 9.52 \\
\hline \multicolumn{2}{|c|}{ Desvio Padrão } & 6,48 & 9,45 & 11,58 & 3,70 \\
\hline \multicolumn{2}{|c|}{ Coef. de Variação } & 0,32 & 4,15 & 1,36 & 1,43 \\
\hline \multicolumn{2}{|c|}{ Eficlência $(\%)$} & 97,70 & 16,55 & 74,43 & 7,21 \\
\hline
\end{tabular}

Uma câmara deste tipo, porém, apresenta dificuldades de ordem prática, como por exemplo seu tamanho, a limpeza, o dispêndio de muito tempo para a preparação de um ambiente, além de precisarmos ter certeza de que todo mercúrio liquido já tenha sido evaporado e disperso homogeneamente no seu interior.

Stettiner ${ }^{1 *}$ descreve um reservatório para produção de concentrações conhecidas de vapores que, no entanto, não é aplicável à produção de vapores de $\mathrm{Hg}$ visto as dificulda- des de trabalhar com pequenos volumes, e pesar pequenas quantidades de mercúrio thetálico da ordem de $1 \mu \mathrm{g}$ que seria evaporado pela corrente de ar que entra para um frasco de atmosfera rarefeita.

Quanto aos resultados obtidos, os meios de solução de iôdo e carvão ativo apresentaram eficiência bastante baixa, e com hopcalita uma eficiência maior, porém, ainda em cerca de $75 \%$. Tal fato poderia ser atribuido inicialmente à baixa produção de rapores de mercúrio por parte do equipa- 
COLACIOrpo, S. Estudo comparativo entre meios de captação de rapores de mercúrio para a. ailação do risco de intoxicação profissional. Rev. Saúde públ., S. Paulo, 11:389-94, 1977.

mento gerador. Esta hipótese, porém, não é confirmada tendo em vista os resultados obtidos com a captação em permanganato. Poderíamos ainda imaginar que a eficiência do meio com permanganato estivese acima dos $100 \%$, o que nos levaria a crer que os demais processos estivessem entáo mais próximos do valor do padrão; porém, com teste em branco com captação e análise exatamente iguais, apenas com ausência de padrão de mercurio, obteve-se resultado praticamente igual a zero, sendo inclusive o teste em branco realizado periodicamente para efeito de detectar possível contaminação.

Outra hipótese que poderia ser levantada a fim de explicar os baixos resultados obtidos, seria uma possível interferência no processo de análise adotado. As substâncias existentes nos processos e que poderiam estar interferindo são: óxido de manganês, oxido de cobre, iôdo, iodeto de potássio e carvão. Segundo Moeller ${ }^{10}$ estas substâncias em solução ácida envolvem potenciais de oxido-redução menores que o do cloreto estanoso, o que significa que poderíamos estar perdendo cloreto estanoso reduzindo outras substâncias além do mercúrio, o que nos daria um resultado analítico inferior ao real, devido a uma liberação parcial do mercúrio em solução. $O$ cloreto estanoso, porém, é adicionado em excesso, o que deve por si contornar este problema. Contudo, para testar a hipótese levantada, foram feitas algumas amostragens utilizando maiores quantidades de solução redutora de cloreto estanoso, o que deveria originar resultados analíticos ao menos ligeiramente maiores, o que não foi verificado.

O meio de adsorção em carvão ativo foi o que menor eficiência apresentou, fato que nos chamou a atenção, visto ser o carvão ativo utilizado em vários processos, inclusive como filtros adsorventes em máscaras para proteção individual.
Em uma tentativa de verificarmos se a cuncentração do ácido nítrico utilizado na eluição de mercúrio do carvão ativo estava interferindo, foram realizadas eluiçôes com ácido clorídrico e com água, não tenco sido detectada grande variação nos resultados, sendo que a eluição com ácido nítrico a $10 \%$ apresentou resultados ligeiramente maiores, para uma mesma quantidade de padrão.

Os baixos resultados obtidos com carvãu ativo concordam com os obtidos por Rathje e col.13, porém, estes mesmos autores afirmam ter obtido eficiências de até $99,9 \%$ com o processo de adsorção em hopcalita, o que não está de acordo com os resultados obtidos de cerca de $75 \%$.

\section{CONCLUSOES}

- O sistema proposto para a produção de vapores de mercúrio conı a finalidade de aferir métodos diferentes de captação funciona satisfatoriamente.

- Dentre us meios de captação estudados, o que utiliza absorção em solução de permanganato de potássio em meio ácido é o de escolha, visto apresentar uma eficiência de aproximadamente $97,7 \%$ e um coeficiente de variação de 0,32 . Se por uma imposição prática, houver necessidade de utilização de um meio de adsorção em amostragem pessoal contínua, o processo que utiliza hopcalita poderá ser escolhido, apesar de sua eficiência ter sido determinada em cerca de $74,4 \%$.

- O processo que utiliza carvão ativo como adsorvente deve merecer maiores estudos quanto à eluição e análise do mercúrio captado, bem como do efeito protetor dos filtros que empregam este material. 
COLACIOPPO, S. Estudo comparativo entre meios de captação de vapores de mercúrio para avaliação do risco de intoxicação profissional. Rev. Saúde públ., S. Paulo, 11:389-94, 1977.

RSPU-B/370

COLACIOPPO, S. [A comparative study among methods of sampling mercury so as to evaluate occupational intoxication risk.] Rev. Saúde públ., S. Paulo, $11: 389-94,1977$.

ABSTRACT: This is a comparative study of the most feasible methods of sampling mercury vapour. Absorption in acid permanganate, absorption in iodine and iodide solutions, adsorption in activated charcoal, and in hopcalite. A process to produce a standard atmosphere of mercury vapour to test the different methods is described. The method showing greatest accuracy and precision was found to be absorption in acid permanganate.

UNITERMS: Mercury poisoning. Industrial medicine. Occuptional diseases.

\section{REFERENCIAS BIBLIOGRÁFICAS}

1. BELL JR., Z. G. et al, Mercury exposure evaluations and their correlation with urine mercury excretions. I - A method to determine mercury timeweighted average (TWA) exposures. $J$. occup. Med., 15:340-2, 1973.

2. HANSON, N. W. et al. The determination of toxic substances in air. Cambridge, Heffer, 1965.

3. HATCH, W. R. \& OTT, W. L. Determination of sub microgram quantities of mercury by atomic absortion spectrofotometry. Analyt. Chem., 40:2085-7, 1968.

4. JACOBS, M. B. The analytical toxicology of industrial inorganio poisons. New York, Interscience, 1967

5. KATZ, M. Measurement of air pollutants: guide to seleotion of methods. Geneve, World Health Organization, 1969.

6. KOTHNY, E. L. A micromethod for mercury. Amer, industr, Hyg. Ass. J, 31: 466-71, 1970 .

7. KRAUSE, L. A, et al. The analysis of mercury in urine, blood, water and air. In: MAYS, E. et al. Mercury poisoning $I$. New York, USS Information Corporation, 1973. v. 1, p. 15-22.

8. MANTELL, C. L. - Adsorption. 2nd. ed. New York, McGraw-Hill, 1951
9. MAYS, E, et al. Determination of mercury in air at university facilities. In: MAYS, E. et al. Mercury poisoning I. New York, USS Information Corporation, $1973 . v, 1$, p. 10-4.

10. MOELIER, T. Quimica inorganica. 3a ed. Barcelona, Ed. Reverté, 1961.

11. PAKTER, M. K. A new method for determination of mercury in air. In: MAYS, E. et al. Mercury poisoning $I$. New York, USS Information Corporation, 1973. v. 1. p. 401-4.

12. PATTY, F. A., ed. Industrial hygiene and toxicology. 2nd ed. New York, Van Nostrand Reinholf, 1969.

13. RATHJE, A. $O$. et al. Personal monitoring technique for mercury vapor in air and determination by flameless atomic absortion. Amer. industr. Hyg. A.ss. J., 35:571-5, 1974.

14. STETTINER, H. M. A. Reservatório para fornecer séries de amostras de ar de composição constante. Rev. Saúde públ., S. Paulo, 4:207-9, 1970.

15. U. S. DEPARTMENT OF HEALTH, EDUCATION, AND WELFARE, Criteria for a recommended standard... occupational exposure to inorganic mercury. Washington, D, C., 1973.

Recebido para publicasão em 08/18/1976 Aprovado para publicasao em 17/12/1976 